\title{
Predictors of Smoking and Alcohol Use in Japanese and Japanese-American College Students
}

\author{
Michiyo Tomioka ${ }^{1}$ and Jay Maddock ${ }^{2}$ \\ ${ }^{1}$ School of Social Work, University of Hawaii \\ ${ }^{2}$ School of Medicine, University of Hawaii
}

\begin{abstract}
This study investigates and identifies the predictors of cigarette smoking and alcohol use and acculturation of Japanese and Japanese American students in Hawaii. The Transtheroetical Model (TTM) was applied to investigate smoking and alcohol behavior and attitudes. A cross-sectional self-report survey was conducted through convenience sampling and the snowball sampling technique. The total 92 participants (Japanese 69.6\%; Japanese Americans 30.4\%) completed either English version or Japanese version of survey. Data were analyzed using analysis of variance, chi-square, and regression to test significance. These analyses indicate that onset of smoking and drinking is associated with Japanese culture. To some extent acculturation is influential factor in both smoking and alcohol behavior. However, nationality and age have stronger associations with smoking; education is stronger factor to predict alcohol use than acculturation among Japanese and Japanese American students. Results indicate a need for cultural-specific interventions for Japanese and Japanese Americans.
\end{abstract}

(C) 2007 Californian Journal of Health Promotion. All rights reserved.

Keywords: Japanese students, smoking, binge drinking, cultural values

\section{Introduction}

Tobacco and heavy alcohol use are major contributors to premature morbidity and mortality in the US. Numerous smoking and alcohol use interventions for adolescents have been implemented to address these behaviors. These actions have succeeded in decreasing the number of smokers and drinkers significantly. However, most interventions are targeted to the general US population, rather than to minority groups (Ma, Shive, Tan, Toubbeh, Fang, \& Edwards, 2005).

In the US, Asians represent only $3.6 \%$ of the entire population (US Census Bureau, 2002). Due to their small numbers, they are often underrepresented in national surveys (Chen, Unger, Cruz, \& Johnson, 1999; Juon, Kim, Han, Ryu, \& Han, 2003; Kuramoto \& Nakashima, 2000; Ma et al., 2005). Since Asian Americans are the fastest growing ethnic minority, it is meaningful to obtain appropriate information to implement culturally sensitive interventions. Common risk behaviors among Asian
Americans are cigarette smoking and alcohol use (Kuramoto \& Nakashima, 2000). Tobacco and alcohol use are shaped by their migratory patterns, acculturation, and history, and their community (Juon et al., 2003). Many factors are associated with problematic behaviors, and each minority group may have a unique attitude toward risk behaviors (Wong, Klingle, \& Price, 2004).

Acculturation refers to the process whereby an immigrant, minority or indigenous group member become fluent in the beliefs, behaviors, and values of the dominant or colonizing culture (Chen et al., 1999). Previous acculturation studies acknowledge different style of acculturation of scales developed to measure acculturation due to different operationalizations. There are inconsistent results because of the complex measurement of acculturation. For example, more frequent English language usage was associated with higher smoking rates among Hispanic and lower rates among Asian men (Chen et al., 1999; Fu, 
Ma, Tu, Siu, \& Meltlay, 2003; Marin, PerezStable, \& Marin, 1989; Moeschberger, Anderson, Kuo, Chen, Wewers, \& Guthrine, 1997). Another study found that English language usage was not associated with smoking among the Vietnamese and Chinese men (Wiecha, Lee, \& Hodgkins, 1998; Yu, Chen, Kim, \& Abdulrahim, 2002). From the studies of length of residency and immigration status (US citizen, permanent resident, and noncitizen) in the US, Asian Americans who have lived here longer and who became US citizens had lower rates of smoking than those who lived here a shorter time (Kim, Yu, Chen, Kim, Brintnall, \& Vance, 2000; Ma, Tan, Tubbeh, \& Su, 2003), while another study found longer time of residency was significantly associated with higher smoking rates among Asian Americans age 21 and under (Ma et al., 2005). Other studies found no association between the years in the US and smoking among Asian Americans (Moeschberger et al., 1997; Wiecha et al., 1998; $\mathrm{Yu}$ et al., 2002). There are fewer examples studies examining alcohol use with acculturation. One study shows that greater English usage and place of birth in the US were associated with highest risk of alcohol use among Asian Americans (Hahm, Lahiff, \& Guterman, 2003). Longer time of residency in the US was associated with greater likelihood of higher alcohol intake among Hispanics (Abraido-Lanza, Chao, \& Florez, 2005).

Hawaii is unique place where a multicultural society exists, so there are some differences between the US mainland and Hawaii. Compared with the nation, Hawaii is a geographical region with a high proportion of Asians (68\%) (US Census Bureau, 2002; Wong et al., 2004). Interestingly, there are many environments in Hawaii where Asian people do not need to adapt to western culture at all. Some people may adopt western culture and Native Hawaiian culture, and others retain their own cultures in this state. Thus, the style of acculturation must be different from other states.

A study of alcohol use and misuse among University of Hawai'i students shows that Japanese students have the highest drinking rates among Asian university students in Hawaii
(Maddock, Glanz, Aganon, \& Araki, 2005). For tobacco use, a previous study indicates Japanese students have the second highest prevalence of lifetime tobacco use among Asians (Hawaii State Department of Health, 2003; Wong et al., 2004). However, only a few studies examine the correlation between acculturation and smoking and alcohol use among Japanese Americans, and none have studied differences between Japanese American students and Japanese (from Japan) students. It is important to examine Japanese students' cigarette smoking and alcohol use with acculturation to develop culture-specific interventions.

\section{Transtheoretical Model}

The transtheoretical model (TTM) examines the process of individual readiness toward specific behavior. In this study, this model identifies the levels of individuals' awareness and attitude toward reducing tobacco and alcohol use. The stages of change are from precontemplation, to contemplation, preparation, action, maintenance, and termination. Precontemplation is the stage in which people do not intend to take action in the foreseeable future. Contemplation is the stage in which people intend to change within the next six months. Preparation is the stage in which people intend to take action in the immediate future, usually defined as the next 30 days. Action is the stage in which people have made specific overt modifications in their lifestyles within the past six months. Maintenance is the stage in which people have made changes for more than 6 months and strive to prevent relapse but do not apply change processes as frequently as do people in action (Prochaska, Redding, \& Evers, 2002). This theory incorporates outcome variables, which are decisional balance and selfefficacy.

Decisional balance reflects the individual's relative weighting of the benefit of changing versus the costs of changing. A self-efficacy component includes the situation-specific confidence that people have that they can cope with high-risk situations without relapsing to their unhealthy behavior. Another factor is temptation to engage in the unhealthy behavior across different challenging situations (Prochaska et al., 2002). This stage model is a 
helpful tool to distinguish the progress of a particular behavior change as individuals pass through from lower stages to advanced stages.

Obtaining information on cigarette smoking and alcohol use and acculturation of Japanese students will reveal Japanese students' patterns of health behavior and relationships between acculturation and smoking status and alcohol use status among these students. The purpose of this research paper is to examine prevalence and stages of change in cigarette smoking and alcohol use and attitudes with acculturation variables.

\section{Methology}

The University of Hawai'i (UH) is one of the major universities where many Asian students study abroad. This study recruited Japanese international students and Japanese American students at the UH through convenient sampling. In this study, Japanese students referred to persons who were born in Japan and raised in Japan. Japanese-American students referred to people who were born in the US and raised in the US. This study assessed their tobacco and alcohol use and readiness to quit based on the TTM and acculturation. The inclusion criteria required that participants must attend either the UH, UH-related community college, or language schools, must be 18 years to 30 years old prior to completion of the survey, and must be Japanese or Japanese American.

\section{Measures}

The cross-sectional self-administered questionnaire was used as a survey instrument. The questionnaire consisted of 77 items including four major components. The components were demographics, alcohol and tobacco use behaviors, the TTM (stage of change, decisional balance, and self-efficacy), and acculturation.

This questionnaire was translated into Japanese and reviewed by Japanese $\mathrm{PhD}$ students at $\mathrm{UH}$ and revised based on the back-translation. The questionnaire was finalized after the pretest. This study provided options for participants of completing the survey in English or in Japanese based on their preferences.

\section{Demographics}

The demographic questions consist of 6 items. The questions asked about the respondent's age, gender, nationality, the place of birth and where they were raised, and education status.

\section{Behaviors}

There were six items for the smoking prevalence and three items for drinking prevalence. The prevalence of tobacco use was assessed and categorized into current smokers, occasional smokers, former smokers, or never smokers. Alcohol use prevalence was assessed and categorized into chronic binge drinkers, occasional binge drinkers, or non bingers. The chronic binge drinkers refer to the respondents who had four or five drinks in one occasion both during the typical day during the school year and during the last 30 days. The occasional binge drinkers refer to the respondents who had four or five drinks in one occasion either during the typical day of the school year or during the last 30 days.

\section{Transtheoretical Model}

Many measurements for attitudes and behavior toward smoking and alcohol are available. In this study, the TTM measurement was adapted from previous studies (Cancer Prevention Research Center, 2005; Chen, Horner, \& Percy, 2003; Maddock et al., 2005). The items were included stage of change, self-efficacy, and decisional balance. To detect the reliability of the scale of decisional balance, the internal consistency reliability coefficient, Cronbach alpha, was conducted and revealed the Pros of smoking and drinking are $\alpha=0.89$ and $\alpha=0.83$. The Cons of smoking and drinking are $\alpha=0.66$ and $\alpha=0.72$. The previous study found the Cronbach alpha as from 0.67 to 0.91 (Chen et al., 2003; Hudmon, Prokhorov, Koehly, DiClemente, \& Gritz, 1997; Lafferty, Heaney, \& Chen, 1999; Migneault, Pallonen, \& Velicer, 1997; Plummer et al., 2001). In exploratory research, a cut-off of $\alpha=0.6$ is reasonable (Garson, 1998). Therefore the decisional balance scale has reasonable internal consistency.

\section{Acculturation}

This study employed the the Suinn-Lew Asian Self-identity Acculturation Scale (SL-ASIA), 
which has been deemed the only validated acculturation measurement for Asian population (Pontero, Baluch, \& Carielli, 1998). The SLASIA consists of 21 items in a multiple choice questionnaire format (Suinn, Richard-Figueroa, Lew, \& Vigil, 1987). This scale measures following variables; language, identity, friendships, behaviors, generational/geographic background, and attitudes. The acculturation score ranges from 1 to 5 with the lower number as less acculturated. Pontero and colleagues (1998) examined reliability and validity of the SL-ASIA and concluded that the measurement has a satisfactory level of reliability and validity for Asian groups. This study obtained 0.95 coefficient alpha, similar to the finding of Suinn, Ahuna, \& Khoo (1992) result (Cronbach $\alpha=$ 0.92).

\section{Analysis}

To summarize data collected for demographic, acculturation status, tobacco use, and alcohol use, standard descriptive statistic were used. The 2 X 2 table was used to assess smoking and alcohol use prevalence among Japanese comparing with Japanese American students at UH. This study examined demographic and acculturation status, using Person chi-square test of significant to assess the differences in stages of change. Logistic regression was used to model the probability of being a smoker or drinking alcohol as a function of acculturation status and demographic. All data were analyzed using SPSS.

\section{Results}

\section{Characteristic of Sample}

This study obtained 92 participants. The English version of survey was completed by 42 participants, and Japanese version of survey was completed 50 participants. Data were collected from 61 Japanese students $(69.6 \%)$ and 28 Japanese American students (30.4\%). The participant characteristics are shown in Table 1.

Table 1

Percentage of smoking and drinking status by demographic characteristics and acculturation status

\begin{tabular}{|c|c|c|c|c|}
\hline $\begin{array}{l}\text { Demographic } \\
\text { Characteristics }\end{array}$ & $\begin{array}{c}\text { Ever Smokers } \\
(64 \%)\end{array}$ & $\begin{array}{c}\text { Never smokers } \\
(36 \%)\end{array}$ & $\begin{array}{c}\text { Ever Drinkers } \\
(92 \%)\end{array}$ & $\begin{array}{c}\text { Never drinkers } \\
(\mathbf{8 \% )}\end{array}$ \\
\hline Age (mean)** & 27.16 & 24.60 & 25.85 & 20.67 \\
\hline \multicolumn{5}{|l|}{ Gender } \\
\hline Male & 27 & 29 & 31 & 0 \\
\hline Female & 73 & 71 & 69 & 100 \\
\hline \multicolumn{5}{|l|}{ Education } \\
\hline Some college & 36 & 12 & 21 & 14 \\
\hline Undergraduate & 27 & 36 & 29 & 71 \\
\hline Graduate & 33 & 36 & 36 & 14 \\
\hline Other & 3 & 17 & 13 & 0 \\
\hline \multicolumn{5}{|l|}{ Nationality* } \\
\hline Japanese & 82 & 63 & 73 & 28 \\
\hline Japanese American & 18 & 37 & 27 & 71 \\
\hline Acculturation (mean) & 2.67 & 2.64 & 2.66 & 2.57 \\
\hline \multicolumn{5}{|l|}{ Length of residency** } \\
\hline Born in the US & 9 & 39 & 25 & 71 \\
\hline Long-term residents & 27 & 14 & 20 & 0 \\
\hline New arrivals & 64 & 47 & 55 & 29 \\
\hline \multicolumn{5}{|l|}{ Language usage* $*$} \\
\hline English $>$ Japanese & 18 & 43 & 30 & 86 \\
\hline English=Japanese & 18 & 21 & 20 & 14 \\
\hline English $<$ Japanese & 64 & 36 & 50 & 0 \\
\hline
\end{tabular}

*: significance at 0.05 -level; $*$ for smoking * for drinking 


\section{Acculturation}

Based on the SL-ASIA's measurement, the average of acculturation score was 2.65 (range $1.44-4.17)$. The majority of students had scores in the middle which indicates bicultural status. There were not significant differences among Japanese $(2.69 \pm 0.91)$ and Japanese Americans

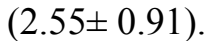

\section{Smoking and alcohol prevalence}

Table 1 is summaries of smoking and alcohol prevalence. Among Japanese students, 24.2\% were current smokers, $16.1 \%$ were former smokers and $59.7 \%$ were never smokers. For Japanese Americans, the majority of students were never smokers $(78.6 \%)$ and the rest were former smokers (21.4\%). The lifetime experience of drinking among Japanese was 96.9\% and Japanese Americans was 82.1\%. Among Japanese participants, 23.1\% were chronic binge drinkers, $24.6 \%$ were occasional binge drinkers and $49.2 \%$ were non bingers. For Japanese American students, $11.1 \%$ were chronic binge drinkers, $33.3 \%$ were occasional binge drinkers and $37 \%$ were non bingers.

Since the sample size was limited, current smokers and former smokers were combined (ever smokers) and chronic binge drinkers, occasional binge drinkers, and non bingers (ever drinkers) are combined for statistical analysis. With nationality variable, smoking status showed anon-significant trend $(\mathrm{p}=0.06)$ and alcohol status was statistically significant $\left(\chi^{2}(1)\right.$ $=6.01, \mathrm{p}=0.01)$. Japanese tend to be ever smokers and ever drinkers. Age was correlated with smoking status $(\mathrm{t}(86)=2.23, \mathrm{p}=0.03)$ and drinking status $(\mathrm{t}(86)=2.39, \mathrm{p}=0.02)$. The people who are older showed higher rates of lifetime smoking and drinking. The resulting scores indicate overall acculturation and gender were not significantly associated with smoking and drinking status.

Since overall acculturation scores was not associated with smoking and drinking status. Some of the specific components of acculturation factors were used to test the correlation. Time of living in the US and English language usage were associated with both smoking status (living $\chi^{2}(2)=9.89, \mathrm{p}<0.01$, English $\left.\chi^{2}(3)=7.33, p=0.03\right)$ and drinking status (living $\chi^{2}(2)=7.26, p=0.03$, English $\chi^{2}$ $(2)=9.55, \mathrm{p}<0.01)$. The never smokers were more likely born in the US and more likely to be English speaking. Ever drinkers were more likely to be recent immigrant and fluent in Japanese.

\section{Transtheoretical Model}

The five stages of change applied to smoking and alcohol use. Due to small sample size, this study is categorized the 5 stages into 3 stages. The difference of contemplation and preparation is the time of intended to quit; contemplation is "within 6 months" and preparation is "within 30 days". The similarity is the individual intend to quit smoking or binge drinking. In addition, the action and maintenance stages are similar in the status of quitting. The difference is the length of time they maintain their quitting. It is reasonable to combine the contemplation and preparation, and action and maintenance. Table 2 summarizes the stage of change in smoking and drinking.

The smoking distribution of stage of change was as follows: $5.6 \%$ in precontemplation, $10.1 \%$ in contemplation \& preparation, $18.0 \%$ in action $\&$ maintenance, and $66.3 \%$ in non smokers. The binge drinking stage of change distribution was as follows: $36.9 \%$ in precontemplation, $8.3 \%$ in contemplation \& preparation, $28.6 \%$ in action $\&$ maintenance, and $26.2 \%$ in non bingers.

Analysis of Variance (ANOVA) identified the relationships between stages, decisional balance and self-efficacy. Positive decisional balance and temptation showed significant differences among both smoking $(\mathrm{F}(2,26)=3.50, \mathrm{p}=0.05, \mathrm{~F}$ $(2,26)=5.09, \mathrm{p}=0.01)$ and drinking stage of change $(\mathrm{F}(3,79)=8.75, \mathrm{p}<0.001, \mathrm{~F}(3,79)$ $=16.18, \quad \mathrm{p}<0.001)$. Furthermore, early stage smokers perceived Pros of this behavior as significantly important to decide to engage in this behavior and less important than the Cons of smoking. Interestingly, early stage of drinkers weighs heavily the Pro concept of drinking. 
However, the aspect of Con of drinking behavior shows consistent level in each stage. Figure 1 and 2 show summary of smoking and binge drinking decisional balance.

Table 2

Percentage of Stage of change in smoking and binge drinking

\begin{tabular}{|c|c|c|c|c|c|c|c|c|}
\hline & \multicolumn{3}{|c|}{ Smoking } & \multicolumn{3}{c|}{ Binge drinking } \\
\hline $\begin{array}{c}\text { Demographic } \\
\text { Characteristics }\end{array}$ & $\begin{array}{c}\text { P } \\
(6 \%)\end{array}$ & $\begin{array}{c}\mathbf{C} \\
(10 \%)\end{array}$ & $\begin{array}{c}\mathbf{A} \\
(18 \%)\end{array}$ & $\begin{array}{c}\mathbf{N} \\
(66 \%)\end{array}$ & $\begin{array}{c}\mathbf{P} \\
(37 \%)\end{array}$ & $\begin{array}{c}\mathbf{C} \\
(8 \%)\end{array}$ & $\begin{array}{c}\text { A } \\
(29 \%)\end{array}$ & $\begin{array}{c}\mathbf{N} \\
(26 \%)\end{array}$ \\
\hline Age & & & & & & & \\
\hline$<21$ & 0 & 11 & 19 & 25 & 19 & 29 & 18 & 5 \\
\hline $22-25$ & 40 & 67 & 19 & 37 & 39 & 57 & 23 & 43 \\
\hline $25<$ & 60 & 22 & 63 & 39 & 42 & 14 & 59 & 52 \\
\hline Gender & & & & & & & & \\
\hline Male & 60 & 0 & 25 & 29 & 35 & 43 & 33 & 14 \\
\hline Female & 40 & 100 & 75 & 71 & 65 & 57 & 66 & 86 \\
\hline Nationality* & & & & & & & & 73 \\
\hline Japanese & 100 & 100 & 63 & 63 & 77 & 57 & 75 & 73 \\
\hline Japanese American & 0 & 0 & 38 & 37 & 23 & 43 & 25 & 27 \\
\hline Education* & & & & & & & & \\
\hline Some college & 20 & 44 & 31 & 12 & 42 & 14 & 17 & 0 \\
\hline Undergraduate & 40 & 44 & 19 & 36 & 29 & 29 & 29 & 32 \\
\hline Graduate & 20 & 11 & 50 & 36 & 26 & 57 & 29 & 50 \\
\hline Other & 20 & 0 & 0 & 17 & 3 & 0 & 25 & 18 \\
\hline Acculturation (mean) & 3.30 & 2.30 & 2.89 & 2.64 & 3.30 & 2.30 & 2.89 & 2.64 \\
\hline
\end{tabular}

$\mathrm{P}=$ Precontemplation, $\mathrm{C}=$ Contemplation \& Preparation, $\mathrm{A}=$ Action \& Maintenance, $\mathrm{N}=$ Non smokers or Non bingers.

*: significance at 0.05 -level; * for smoking; * for drinking

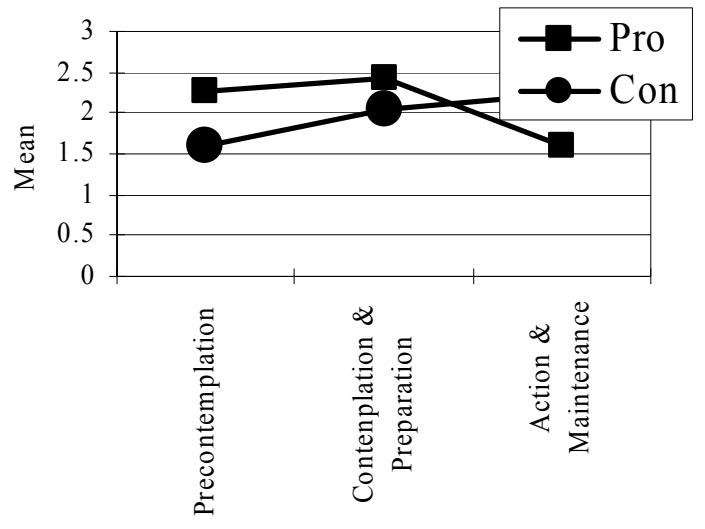

Figure 1

Decisional balance weight in smoking 


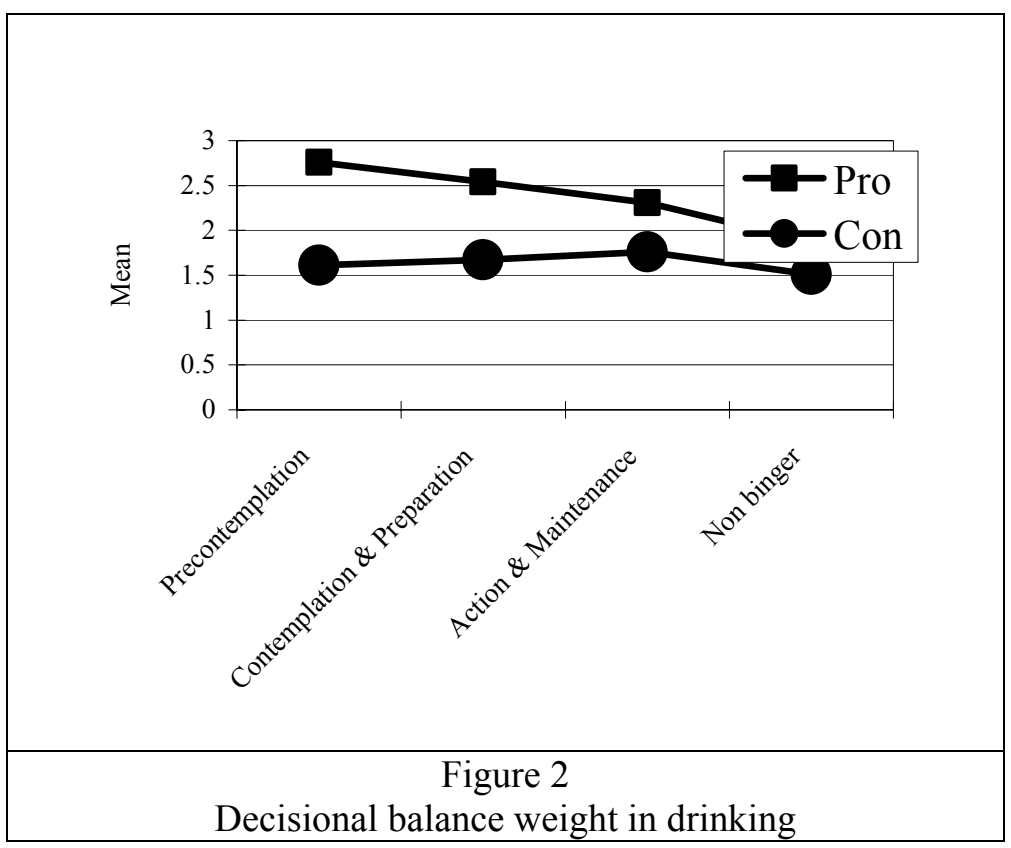

Stages of change in smoking behavior was associated with nationality $\left(\chi^{2} \quad(2)=6.56\right.$, $\mathrm{p}=0.04)$. The respondents in advanced stages were more likely to be Japanese American and have graduate level of education. The stages of change in binge drinking was associated with only education $\left(\chi^{2}(6)=13.22, p=0.04\right)$. The participants in advanced stages were more likely to have graduate level of education. Both smoking and drinking stages of change showed no association with total score of acculturation.

\section{Predictors of smoking and drinking}

To analyze the predictors of smoking and binge drinking, logistic regression analysis were applied because independent variables are dichotomous. Based on the assumption, the predictor variables include age, gender, nationality, and acculturation status. Logistic regression indicates that smoking status is not predicted by age, gender, nationality, and acculturation. In drinking status, after including acculturation, age, gender, and nationality, acculturation was not significant predictor $(\mathrm{p}=$ 0.858). But age turns out the stronger predictor $(\mathrm{p}=0.037)$ than any other factors for drinking alcohol.

\section{Discussion}

\section{Prevalence: Smoking}

The overall majority of Japanese and Japanese Americans are not current smokers. Japanese indicates higher percentage of lifetime smoking experience and less likely to quit than Japanese Americans. Older individuals were more likely to be smokers and ex-smokers. Although the reliability of the acculturation scale was evaluated and verified, the overall acculturation status was not associated with smoking status. Associated variables in acculturation scale are language usage and time of living in the US. Some researchers consider English usage or time of living in the US as acculturation, but the results are inconsistent among the ethnicity. This study suggests the students who frequently use English and live longer in the US are less likely to become smokers. This may be explained by the high level of education and public awareness of risk of smoking in Hawaii so that they have fewer tendencies to begin smoking and higher rates of quit smoking than Japanese. Although Japanese society has become aware of necessity of anti-smoking education, Dando (2003) explains Japanese anti-smoking education is not adequate; they educate as 'be careful when you smoke' instead of 'do not smoke for your entire 
life'. This style of anti-smoking education may partly explain why Japanese have lower rates of quitting.

\section{Prevalence: Drinking}

The overall majority of Japanese and Japanese American students have lifetime drinking experience, as similar to the finding from the report of UH alcohol usage (Maddock et al., 2005). Japanese $(96.9 \%)$ have more experience with drinking than Japanese Americans (82.1\%). The age variable turns out the stronger factor than others. Older people are more likely to consume alcohol. This is inconsistent with previous studies (Jernigan, 2001; Landrine \& Klnoff, 2004). The reason for the inconsistency is that the Japanese may have different patterns of drinking, compared with Americans (Higuchi, Parrish, Dufour, Towle, \& Harford, 1994), and older people may have more opportunity to drink alcohol than younger people in a Japanese community. On the other hand, this study reveals that younger people have higher number of drinks than older people. The older people tend to drink but they are more likely to limit the number of drinks and younger people tend to have different patterns of drinking such as when they turn to 21 , many tend to celebrate their legal age or people who are under the legal age want to drink as much as they can when they have opportunity.

In term of acculturation, this study revealed frequent Japanese language usage and recent arrival to the US are related with lifetime drinking experience. The finding of language usage is opposing to previous study findings that English usage is associated with alcohol consumption (Hahm et al., 2003; Makimoto, 1998). It could partly explain that acculturation influences drinking behavior among Japanese students in both directions. Some Japanese who become acculturated may also accept the westernized alcohol culture. Other Japanese may have difficulty to adapt the new culture and vented their stress by drinking. The international students face so many challenges, such as perceived difficulties in adaptation of new culture and English proficiency, than domestic students (Kramer, Prufer-Kramer, Stock, \& Tshiananga, 2004). These challenges might be the cause of stress (Constantine, Okazaki, \& Utsey, 2004; Maundeni, 2001; Poyrazil, Kavanaugh, Adria, \& Al-Timimi, 2004; Yeh \& Inose, 2003).

\section{Transtheoretical Model: Smoking}

The TTM explains that people engage in risky behaviors when in the difficult situations (Prochaska et al., 2002). Japanese and Japanese American distribution in stages is different. Japanese lifetime smokers tend to be gradually increase proportion of rates toward more advanced stages. All Japanese American lifetime smokers in this sample were in the action and maintenance stages.

The movements of stage of change were identified by using decisional balance scale and temptation scale. In this study, smokers weight positive aspect of smoking, and then shift to negative aspect of smoking with stages. When looking at specific score of negative decisional balance, it gradually increases and takes over the positive aspect of smoking behavior. However, the negative aspect of smoking was not significantly associated with stage of change. The previous study also suggested that the negative aspect of smoking is not stronger factor than positive aspect of smoking (Lafferty et al., 1999). Similar to other studies findings (Keller \& McGowan, 2001; Prochaska et al., 2002), this study supports theoretical concept that decisional balance of weighting is gradually changed from precontemplation to maintenance stage. Smokers in the later stages also reported less temptation to smoke. Therefore, this study found theoretical concept that people in advanced stage shows less level of temptation in smoking.

In sum, smoking is very serious problem among Japanese students. It seems people who come to the US are not likely to initiate smoking; their smoking behavior is already developed before coming to the US. The study found it is necessary to target Japanese students who have already smoked. Even though the UH regulates smoking policy on campus, Japanese students have less influence from the new policy. It is necessary to focus on the new students from Japan to increase awareness of risk of smoking 
including second hand smoke. This study calls attention to developing smoking cessation materials for Japanese students since many of them are already smokers before they arrive in the US.

\section{Transtheoretical Model: Drinking}

Most of the participants are in precontemplation $(36.9 \%)$, action and maintenance $(28.6 \%)$ or non-binger stages $(26.2 \%)$. It implies that the people are either high risk of binge drinkers or non-risk of binge drinkers, and drinkers do not intend to change their pattern of drinking behavior among Japanese and Japanese American students. People in graduate level tend to be in higher stages than people in community college level. It confirms that the people who are higher level of education are less likely to engage in risk behavior (McPhee, Jenkins, \& Wong, 1995; Wiecha et al., 1998).

In this study, as in previous research (Carbonari, \& DiClemente, 2000), people become less tempted in drinking situation in advanced stages. The decision making process of drinking was also evaluated and found different result from previous study. The previous study presented that people in the low stages endorsed less negative aspects of drinking (Migneault et al., 1997). Positive aspect of drinking behavior decrease with advanced stages. The unique finding of this research is people do not weight drinking as negative aspect when they intend to quit this behavior. The reason for negative aspect of drinking was different from previous studies is that this study focused on Japanese and not Caucasians. Japanese culture involves alcohol in traditional events so that Japanese people tend to evaluate drinking behavior by weighting heavily on positive perspective. Japanese immigrated to Hawaii a long time ago, and have been here for more than four generations and became majority of ethnic group. Some of the Japanese Americans still maintain the Japanese tradition (Kuramoto \& Nakashima, 2000) and they also maintain traditional Japanese style in Hawaii. Therefore, the negative aspect of drinking was very low in each stage because of the norm of drinking differs from Western culture. This cultural differences influence the decision making process and vary among different ethnic groups (Lafferty et al., 1999).

Drinking is also very serious problem among Japanese students and younger students. It is necessary to enforce the prevention programs of binge drinking among young students and Japanese students. The UH established Alcohol/Drug policies on campus, but many people do not involve in prevention activities (Maddock \& Glanz, 2005). To prevent the binge drinking among Japanese and Japanese Americans, the programs or policy need to respect the positive aspect of drinking and focus on reducing the positive aspect of drinking, not enforce negative aspects. Current policy and prevention programs emphasis on increase the negative aspect of drinking. However, this study suggests the development of Japanese specific programs because of different attitude toward drinking.

\section{Conclusions and Recommendations}

Smoking and heavy drinking problems among young people are very important in health science research field. This study investigates predictors of smoking and alcohol behaviors among Japanese and Japanese American students in college. This study found to some extent acculturation influences were either positive or negative for smoking and drinking. For smoking, the mainstream culture of not smoking in Hawaii has positive influence on Japanese students. The drinking norm of US may have a negative influence on Japanese students. This study recommends developing specific prevention or intervention programs for Japanese international students to support their difficulty to adapt new culture and also to promote healthy behaviors. The results of study did not show acculturation as a stronger predictor than education, but showed that acculturation is a very complex mechanism, and it is difficult to assess the integrated variety of levels and components of acculturation.

There are several factors to improve this study due to limitations and resulting problems. The first limitation is sample size and sampling technique. Since this study focuses on a specific population, participants had to be recruited 
though e-mail services and a snowball technique instead of collecting sample at classes as typical sampling method. People did not respond through the e-mail system due to numerous spam mails. Also the sampling method yielded a larger proportion of Japanese students and graduate students than those of Japanese American students and other educational status, respectively. As a result, this study had a limited sample size. The limited sample size and uneven proportional rate made it difficult to evaluate the acculturation influence. Hence, it is necessary to consider better and more effective sampling techniques in answering the research questions posed by this study.

The other limitations are operationalization of acculturation and cross-sectional study. The definition of acculturation differs in previous studies. Despite this study intended to measure multiple variables of acculturation, overall acculturation did not show strong association between risk behaviors. Some of the acculturation variables show the significant correlations. The inconsistent result may imply that we must reconsider the definition of acculturation. In addition, the process of acculturation may vary among individuals, and it is not a short-term influential factor, so that it might be difficult to draw conclusion about the acculturation process based on a cross-sectional study design.

There are limitations and problems in this study. Nevertheless, the results of this study provide very interesting insights about the relationship between acculturation and smoking and alcohol use among Japanese and Japanese Americans. Studying those relations in other states or with other ethnic groups may reveal and distinguish between the regional differences and ethnicity differences. These extended studies will provide more clear definitions of acculturation and how acculturation differs from ethnicity.

\section{References}

Abraido-Lanza, A. F., Chao, M. T., \& Florez, K. R., (2005). Do healthy behaviors decline with greater acculturation? Implications for the Latino mortality paradox. Social Science and Medicine, 61, 1243-1255.

Cancer Prevention Research Center (2005). Measures. Retrieved September 2, 2005, from http://www.uri.edu/research/cprc/measures.htm

Carbonari, J. P., \& DiClemente, C. C. (2000). Using transtheoretical model profiles to differentiate levels of alcohol abstinence success. Journal of Consulting and Clinical Psychology, 68, 5, 810-817.

Chen, H., Horner, S. D., \& Percy, M. S. (2003). Cross-Cultural validation of the stages of the tobacco acquisition questionnaire and the decisional balance scale. Research in Nursing \& Health, 26, 233-243.

Chen, X., Unger, J. B., Cruz, T. B., \& Johnson, C. A. (1999). Smoking patterns of Asian-American youth in California and their relationship with acculturation. Journal of Adolescent Health, 24, 321-328.

Constantine, M. G., Okazaki, S., \& Utsey, S. O. (2004). Self-concealment, social self-efficacy, acculturative stress, and depression in African, Asian, and Latin American international college students. American Journal of Orthopsychiatry, 74, 3, 230-241.

Dando, Y. (2003). Japanese people who don't grow out of dependency on tobacco. Retrieved April 28, 2006, from http://dandoweb.com/e/tobacco.html

Fu, S. S., Ma, G. X., Tu, X. G., Tu, X. M., Siu, P. T., \& Metlay, J. P. (2003). Cigarette smoking among Chinese Americans and the influence of linguistic acculturation. Nicotine and Tobacco Research, $5,6,803-811$.

Garson, G. D. (1998). Reliability. Retrieved April 28, 2006, from http://www2.chass.ncsu.edu/garson/pa765/reliab.htm

Hahm, H. C., Lahiff, M., \& Guterman, N. B. (2003). Acculturation and parental attachment in AsianAmerican adolescent' alcohol use. Society for Adolescent Medicine, 33, 119-129. 
Hawaii State Department of Health. (2003). Smoking and tobacco use in Hawaii: Facts, figures, and trends. Hawaii: Tobacco prevention and education program. Hawaii: Chronic Disease Management and Control Branch, and Hawaii State Department of Health.

Higuchi, S., Parrish, K. M., Dufour, M. C., Towle, L. H., \& Harford, T. C. (1994). Relationship between age and drinking patterns and drinking problems among Japanese, Japanese Americans, and Caucasians. Alcoholism: Clinical And Experimental Research, 18, 305-310.

Hudmon, K. S., Prokhorov, A. V., Koehly, L. M., DiClemente, C. C., \& Gritz, E. R. (1997). Psycholometric properties of the decisional balance scale and the temptations to try smoking inventory in adolescents. Journal of Child \& Adolescent Substance Abuse, 6, 1-18.

Juon, H., Kim, M., Han, H., Ryu, J. P., \& Han, W. (2003). Acculturation and cigarette smoking among Korean American men, Yonsei Medical Journal, 44, 875-882.

Jernigan, D. H. (2001). Global status report: Alcohol and young people. Geneva: World Health Organization.

Keller, C. S., \& McGowan, N. (2001). Examination of the processes of change, decisional balance, selfefficacy for smoking and stages of change in Mexican American women. Southern Online Journal of Nursing Research, 4, 1-31. Retrieved April 10, 2006, from http://www.snrs.org/publications/SOJNR articles/iss04vol02.pdf

Kramer, A., Prufer-Kramer, L., Stock, C., \& Tshiananga, J. T. (2004). Differences in health determinants between international and domestic students at a German University. Journal of American college health, 53, 127-132.

Kim, K. K., Yu, E. S., Chen, F. H., Kim, J., Brintnall, R., \& Vance, S. (2000). Smoking behavior, knowledge and beliefs among Korean Americans. Cancer Practices, 8, 223-230.

Kuramoto, F. \& Nakashima, J. (2000). Developing an ATOD Prevention Campaign for Asian and Pacific Islanders: Some considerations. Journal of Public Health Management Practice, 6, 3, 57-64.

Lafferty, C. K., Heaney, C. A., \& Chen, Jr., M. S. (1999). Assessing decisional balance for smoking cessation among Southeast Asian males in the US. Health Education Research, 14, 139-146.

Landrine, H., Klonoff, E. A. (2004). Culture change and ethnic-minority health behavior: An operant theory of acculturation. Journal of Behavioral Medicine, 27, 527-555.

Ma, G. X., Shive, S. E., Tan, Y., Toubbeh, J. I., Fang, C. Y., \& Edwards, R. L. (2005). Tobacco use, secondhand smoke exposure and their related knowledge, attitudes and behaviors among Asian Americans. Addictive Behaviors, 30, 725-740.

Ma, G. X., Tan, Y., Tubbeh, J., \& Su, X. (2003). Differences in stages of change of smoking behavior among current smokers of four Asian American subgroups. Addictive Behaviors, 28, 1431-1439.

Maddock, J., Glanz, K., Aganon, E. M., \& Araki, C. (2005). Climate check-up improving campus health. Hawaii: Prevention and Control Program, Cancer Research Center of Hawaii, and University of Hawai'i at Manoa.

Maddock, J., \& Glanz, K. (2005). The relationship of proximal normative beliefs and global subjective norms to college students' alcohol consumption, Adductive Behaviors, 30, 315-323.

Makimoto, K. (1998). Drinking patterns and drinking problems among Asian-Americans and Pacific Islanders, Alcohol Health \& Research World, 22, 270-275.

Marin, G., Perez-Stable, E. J., \& Marin, B. V. (1989). Cigarette smoking among San Francisco Hispanics: The Role of Acculturation and Gender. American Journal of Public Health, 79, 196-199.

Maundeni, T. (2001). The role of social networks in the adjustment of African Students to British society: Students' perception. Race Ethnicity and Education, 4, 253-276.

McPhee, S. J., Jenkins, C. N., \& Wong, C. (1995). Smoking cessation intervention among Vietnamese Americans: A controlled trial. Tobacco Control, 4 (Suppl. 1), S16-S24.

Migneault, J. P., Pallonen, U. E., \& Velicer, W. F. (1997). Decisional balance and stage of change for adolescent drinking. Addictive Behaviors, 22, 339-351.

Moeschberger M. L., Anderson, J., Kuo Y. F., Chen, M. S., Wewers, M. E., \& Guthrie, R. (1997) Multivariate profile of smoking in Southeast Asian men: a biochemical verified analysis. Preventive Medicine, 26, 53-58. 
Pontero, J. G., Baluch, S., \& Carielli, D. (1998). The Suinn-Lew Asian Self-identity Acculturation Scale (SL-ASIA): Critique and research recommendations. Measurement and Evaluation in Counseling and Development, 32, 109-124.

Poyrazil, S., Kavanaugh, P. R., Adria, B., \& Al-Timimi, N. (2004). Social support and demographic correlates of acculturative stress in international students. Journal of College Counseling, 7, 7382.

Prochaska, J. O., Redding, C. A., \& Evers, K. E. (2002). Health Behavior and Health Education. In K. Glanz, B. K. Rimer, and F. M. Lewis (Ed.), The transtheoretical model and stages of change (pp. 99-120) San Francisco: Jossey-Bass.

Plummer, B. A., Velicer, W. F., Redding, C. A., Prochaska, J. O., Rossi, J. S., Pallonen, U. E. et al. (2001). Stage of change, decisional balance, and temptations for smoking measurement and validation in a large school-based population of adolescents. Addictive Behaviors, 26, 551-571.

Suinn, R. M., Rickard-Figueroa, K., Lew, S., \& Vigil, P. (1987). The Suinn-Lew Asian Self-identity Acculturation Scale: An initial report. Educational and Psychological Measurement, 47, 401-407.

Suinn, R. M., Ahuna, C., \& Khoo, G. (1992). The Suinn-Lew Asian Self-Identity Acculturation Scale: Concurrent and factorial validation. Educational \& Psychological Measurement, 52, 1041-1046.

US Census Bureau. (2002). The Asian population: 2000. Retrieved September 6, 2005, from http://www.census.gov/prod/2002pubs/c2kbr01-16.pdf

Wiecha, J. M., Lee, V., \& Hodgkins, J. (1998). Patterns of smoking, risk factors for smoking, and smoking cessation among Vietnamese men in Massachusetts (United States). Tobacco Control, 7, 27-34.

Wong, M. M., Klingle, R. S., \& Price, R. K. (2004). Alcohol, tobacco, and other drug use among Asian American and Pacific Islander Adolescents in California and Hawaii. Addictive Behaviors, 29, 127-141.

Yeh, C. J. \& Inose, M. (2003). International students' reported English fluency, social support satisfaction, and social connectedness as predictors of acculturative stress. Counseling Psychology Quarterly, 16, 15-28.

Yu, E. S. H., Chen, E. H., Kim, K. K., \& Abdulrahim, S. (2002). Smoking among Chinese Americans: Behavior, knowledge, and Beliefs. American Journal of Public Health, 92, 1007-1012.

\title{
Acknowledgements
}

I would like to express my appreciation to all who contributed to this thesis and in particular to Dr. Jason Maddock, whose thorough public health knowledge and valuable academic advice have contributed to the realization of this project. Many thanks also go to the committee members, Dr. Kathryn Braun and Dr. John Grove, for their advice and comments on this study. I also would like to thank Fumiko, Dennis, HeeSeon, Chieko, Nurdiyanah, Nandar who helped me to complete this study. This study was based on the Master's thesis of the first author.

\author{
Author Information \\ Michiyo Tomioka, MS* \\ University of Hawaii \\ 1800 East-West Road \\ Henke Hall \\ Honolulu, HI 96822 \\ E-Mail: mtomioka@,hawaii.edu \\ Jay Maddock, Ph.D. \\ University of Hawaii \\ 1960 East-West Rd. \\ Biomed D209E
}


M. Tomioka \& J. Maddock / Californian Journal of Health Promotion 2007, Volume 5, Issue 2, 45-57

Honolulu, HI 96822

E-Mail: jmaddock@hawaii.edu

* corresponding author 